\title{
Pulp in the ivory tower One university library's development of a pulp magazine collection from scratch
}

$\mathbf{T}$ he postmodern collapse of the distinction between the high- and low-brow has brought about renewed scholarly attention to pulp magazines, which flourished from the early 1920 s to the late 1930s and survived until the late 1950s. The magazines were produced on inexpensive pulp paper (hence their name) and featured sensational works of crime, adventure, Western, science fiction, and romance fiction. They are also notable for their imaginative, vibrant, and often tawdry cover illustrations. Because they were deemed culturally disposable at the time and were made on such low-quality paper, limited numbers of originals have been collected by libraries despite the fact that numerous pieces by now-canonical writers such as Dashiell Hammett, Raymond Chandler, Robert E. Howard, H. P. Lovecraft, and Hugo Gernsback, just to name a few, graced their pages. Contemporary literary, gender, art, and cultural studies scholars are now looking back to the pulps as valuable resources that provide insight into the values and practices of early 20th-century popular and mainstream culture.

James Madison University (JMU) Library's Special Collections began collecting notable pulp magazines in 2011, in collaboration with English professor Brooks Hefner, who does scholarly research on the subject. Notable issues of highly sought- after titles such as Black Mask, Amazing Stories, and Weird Tales were soon added to the collection. During this process, which included several donations, JMU's collection of pulp magazines has become one of the strongest in the United States with nearly 600 items. Collecting in this area presents numerous challenges for the library and the English Department, such as developing broader uses for the collection, collection development, preservation, providing access, copyright issues, advocacy, and budget constraints. In this piece, we discuss the evolution of this collaboration, the challenges mentioned above, and our plans for the collection moving forward.

In 2010, the Collection Development Committee at JMU Libraries procured the funds to create a Special Project Funding Grant. Hefner, who counts pulp magazines among his scholarly interests, proposed a special project to develop a pulp magazine collection at JMU. In collaboration with the former liaison librarian to the English Department, Melissa Van Vuuren (now the English and Humanities librarian at George-

Brian Flota is humanities librarian, email: flotabc@jmu.edu, Mark Peterson is formerly rare books and research services librarian, now graduate student, email: peter3me@jmu. edu, and Julia Merkel is preservation officer, email: merkeljm@jmu.edu, at James Madison University

(c) 2016 Brian Flota, Mark Peterson, and Julia Merkel 
town University), the grant was approved and an initial purchase of important issues of Black Mask were received beginning in early 2011. Since then, key issues of the magazine have been acquired, such as one of the four issues of Hammett's first novel Red Harvest (1927-

28), the first three of five issues containing Hammett's novel The Maltese Falcon (1929), two of five issues containing Hammett's The Glass Key (1930), and the infamous $\mathrm{Ku}$ Klux Klan issue of June 1, 1923, which features the first Race Williams story (a creation of Carroll John Daly, Williams was the most popular fictional hardboiled private detective in the 1920 s and 1930s). Other important acquisitions include issues of Weird Tales and Astounding Stories with fiction by Howard, Lovecraft, and L. Ron Hubbard (including the first publication of "Dianetics" in the May 1950 issue of Astounding Science Fiction), as well as provocative cover art by Margaret Brundage.

\section{Scholarship and the pulps}

There are several scholarly reasons for initiating this collection. Interest in less "highbrow" creative writing has blossomed since the 1980s. Similarly, as works by long-canonized writers became critically exhausted, younger and more adventurous scholars started looking elsewhere for scholarly subjects. The more popular pulp magazines had circulation numbers as high as 200,000 per issue during the peak of their popularity in the 1920s and 1930s. As numerous pulp scholars have pointed out, the pulps did have an important influence on numerous canonized writers of the modernist era.

One such example includes William Faulkner's early novel Sanctuary (1931), which, scholar Walter Wenska argues, draws plenty of influence from the pulps. ${ }^{1}$ Furthermore, the pulps offer a variety of content to examine. Not only do they feature popular fiction, but they also possess lurid cover art and interior illustrations, letters sections that provide contemporary readers' responses to fiction from the era, and quirky advertisements. Analysis of single issues or runs of issues can yield complex analyses ranging from pulp poetics and gender roles to graphic design and the deployment of colonialist tropes.

Hefner cites a number of reasons why academic libraries should collect them. For most scholars, it is a format that one can examine to find the intersections between high and low culture. As writers such as Hammett and Gernsback become more fully entrenched in the canon, examining original issues of the pulps provides context for their popularity, much in the same way the so-called "little magazines," like The Dial, Contempo, The Smart Set, and The New Masses, helped build the reputations and audiences of high modernists such as T. S. Eliot, Ezra Pound, H. D., Marianne Moore, and James Joyce. Studying 
the pulps helps contemporary scholars get back in touch with a large group of readers who have been pushed to the peripheries of history because of the continued focus on the most privileged group of readers: the educated, the wealthy, and the artisan classes. Pulps can be a more effective way of gauging cultural anxieties than literary classics because of the speed with which they were produced and published. Highbrow works of fiction often take much longer to conceive, write, and publish. Furthermore, a cursory search of the term "pulp" presently turns up 507 results in the MLA International Bibliography database from 2000 to 2016 (excluding those specifically about Quentin Tarantino's 1994 film Pulp Fiction). This is an expanding field in literary studies, which has broader applications to American Studies, Cultural Studies, Media Studies, and many other interdisciplinary fields of study.

\section{Promoting and preserving the collection}

Because of the pulps' often dramatic covers, with their explosive colors, Special Collections has put issues of the pulps on display at every general exhibit and class session in the last five years, generating a great deal of excitement. Several articles about the collection and its use in classes have appeared in campus publications, including JMU promotional sites. JMU Libraries have also sponsored three presentations by scholars on the pulp collection in that time. The Special Collections blog has covered the pulps frequently, and Brian Flota's LibGuide "Pulp Magazines" shows students how to use them successfully for primary source research. ${ }^{2}$

JMU Special Collections, headed by Lynn Eaton since 2013, has purchased these items to be used in classes. While every effort is made to preserve the issues, we also recognize that this use is going to damage the magazines over time. The paper and glue have become brittle enough that every use breaks off tiny fragments. We work to keep the magazines together as long as possible. Everyone who comes into the reading room to work with this material is taught how to handle the fragile paper and spines of the pulps carefully.

Pulp paper has high lignin and acidic content. Because of this, we store each item in a fourfold pamphlet or document binder constructed from 60-point acid and lignin-free boards with 10-point interior flap enclosures. The $\mathrm{pH}$ neutral materials are also buffered with 3\% calcium carbonate to help minimize the effects of pollutants in the air and to minimize acid migration from the pulps themselves. In cases where the cover has separated from the text block, our preservation officer, Julia Merkel, either reattaches the cover to the text block with a reversible wheat paste adhesive or encloses the cover in a separate polyester sleeve when more protection is warranted.

Special Collections storage is also monitored for temperature, humidity, and insect activity. We strive for a cool and dry environment in an interior stack level with a temperature below $70^{\circ}$ Fahrenheit and relative humidity below $50 \%$, which is a challenging in an aging, multi-use building (that includes a coffee shop).

Promoting the collection, especially the content of the pulp magazines, presents notable challenges. As mentioned above, the brittle condition of many of the pulps makes long-term preservation a legitimate concern. Furthermore, digitization projects are not yet possible because most of the key pulp titles and issues were published after 1923 and are still in copyright. This essentially limits us to posting scans of cover art on our various library websites for the issues that we own.

Once the copyright lapses, we are still faced with the challenge of how to adequately handle pulp magazines during any potential digitization process, as brittle paper and bindings could be damaged in the effort to make high- quality scans of the magazines in our collection. Any extensive digitization project would be difficult due to the lack of staffing available to undertake such a project.

Special Collections has acquired much of the pulp collection by having alerts on 
popular auction sites online for specific dates and periodically looking through the major titles that are available. Faculty members periodically let us know of specific issues for sale that they would like us to consider, as well. The most successful purchases have come from identifying booksellers with plenty of pulps in stock and letting them know that JMU would like purchase a bulk order with less concern for condition than many individual collectors. Thanks to on-campus publicity regarding our collection of pulps, a number of donations have been made. Larry Huffman, adjunct faculty member in the Department of Educational Foundations and Exceptionalities at JMU, gave Special Collections nearly 100 Western pulps from the 1940s and 50s.

Between 2011 and February 2016, our collection of Amazing Stories, Black Mask, and Weird Tales titles were used 483 times. In July 2015, independent researchers unaffiliated with JMU began using the collection for the first time. Several JMU faculty members have used the pulps for research in the past five years. Though usage has exceeded expectations, we still need to work more with faculty who have an interest in the collection to make it fit with their teaching programs. Additionally, we need to publicize these resources to pulp researchers around the country.

\section{Plans for the collection}

Going forward, the plan is to continue to search for stories from major writers in our three main titles and fill in the different decades of our holdings, starting with 1929 to 1939 , with an eventual eye on getting more good examples from each period. This has to be done with some care, since there are always issues from our three titles available, but not necessarily the best ones for our developing collections. We are also beginning to explore collecting back issues of less revered pulps titles such as Adventure, Astonishing Tales, Detective Story, Dime Mystery, Doc Savage, Horror Story,
Love Story (which we recently acquired 90 issues of), The Shadow, and Western Story, just to name a few. The budget for building this collection has been modest (though it has grown over the last few years). English and History librarians have contributed funds toward several major purchases that have helped us get major issues and some bulk purchases to support the university's teaching and faculty research.

One way we plan on promoting the collection is to host a conference based around our collection of pulp magazines. The first annual Pulp Studies Symposium: Sensation Scholarship will be held at JMU on October 7 and 8, 2016. We have assembled a task force of notable pulp scholars to help identify potential participants, keynote speakers, advertising venues, and fundraising partners to assist us in the endeavor. Ideally, participants in the conference will include scholars, booksellers, collectors, librarians, fans, and others interested in the pulps. This conference will attach high scholastic value to the collection and has the potential to attract more outside scholars, future donors, and form relationships with other institutions collecting pulp magazines.

This is a project clearly worth continuing. As works and perspectives on high modernist authors become exhausted, the writings of more obscure popular writers from the era will provide a fresh resource for literary historians, popular cultural studies, and many other interdisciplinary scholars. We hope to continue to grow the collection to not only serve our faculty, but also the broader, growing scholarship on the pulps and more popular forms of expression in general. $\boldsymbol{n}$

\section{Notes}

1. Walter Wenska, “'There's a Man With a Gun Over There': Faulkner's Hijackings of Masculine Popular Culture," Faulkner Journal 15.2 (1999/2000): 35-60.

2. Pulp Magazines LibGuide, http:// guides.lib.jmu.edu/pulpmagazines. $\boldsymbol{n}$ 